\title{
Hubungan Keterampilan Tekhnik Menyusui dengan Kejadian Puting Susu Lecet pada Ibu Post Partum
}

\author{
Relationship between Breastfeeding Technical Skills and The Event of Milk \\ Nipples Blisters on Post Partum Mothers
}

\author{
Ulfa Farrah Lisa ${ }^{* 1}$, Noerma Ismayucha ${ }^{2}$ \\ ${ }^{1}$ Program Studi D-IV Bidan Pendidik, Fakultas Ilmu Kesehatan, Universitas Ubudiyah Indonesia, Banda Aceh, Indonesia \\ ${ }^{2}$ Program Studi D-III Bidan Pendidik, Fakultas Ilmu Kesehatan, Universitas Ubudiyah Indonesia, Banda Aceh, Indonesia \\ * Korespondensi Penulis: ulfa.feliz@gmail.com
}

\begin{abstract}
Abstrak
Menurut Profil Kesehatan Aceh Tahun 2011 bayi yang mendapat ASI eksklusif baru mencapai 11,9 \%. Data Puskemas Peukan Bada menunjukkan pada tahun 2015, dari 426 ibu melahirkan terdapat $142 \mathrm{ibu}$ yang menyusui bayinya (30\%). Salah satu alasan ibu tidak menyusui bayinya yaitu karena ASI tidak lancer dan puting susu lecet. Metode penelitian ini menggunakan desain cross sectional, dilakukan pada tanggal 15 s.d 28 Desember 2016 di Wilayah Kerja Puskesmas Peukan Bada. Subjek dalam penelitian ini adalah ibu post partum 0-40 hari yang berada di Wilayah Kerja Puskesmas Peukan Bada pada bulan Desember tahun 2016. Jumlah ibupost partum 40 orang. Penelitian ini mengambil seluruh populasi (total population) pada bulan Desember 2016. Analisa data menggunakan analisa univariat dan bivariat, dimana uji statistik menggunakan uji chi square. Hasil Penelitian menunjukkan bahwa kejadian puting susu lecet lebih banyak di jumpai pada responden dengan keterampilan kurang yaitu $86 \%$ dibandingkan dengan responden yang keterampilan baik yaitu $20 \%$, dengan nilai $\mathrm{p}=0,001$. Ada hubungan keterampilan teknik menyusui dengan kejadian puting susu lecet pada ibu nifas. Diharapkan agar tenaga kesehatan dapat memberikan pendidikan kesehatan tentang bagaimana teknik menyusui yang benar sehingga meningkatkan keterampilan ibu dalam menyusui sebagai salah satu upaya mengurangi kejadian putting susu lecet dan suksesnya pemberian ASI eksklusif.
\end{abstract}

Kata Kunci: keterampilan teknik menyusui, kejadian putting susu lecet

\section{Abstract}

According to the Aceh Health Profile In 2011, infants who received exclusive breastfeeding only reached 11.9\%. Peukan Bada Community Health Center data shows that in 2015, of 426 mothers giving birth there were 142 mothers who breastfed their babies (30\%). One reason mothers do not breastfeed their babies is because the milk is not smooth and the nipples are blisters. This research method used a cross sectional design, carried out on the 15th of December 28th, 2016 in the Peukan Bada Health Center Working Area. The subjects in this study were post-partum mothers 0-40 days who were in the Peukan Bada Community Health Center Working Area in December 2016. The total number of participants was 40 people. 
This study took the entire population (total population) in December 2016. Data analysis using univariate and bivariate analysis, where statistical tests using the chi square test. The results of the study showed that the incidence of blisters nipples was more common in respondents with less skills, namely $86 \%$ compared to respondents who had good skills of $20 \%$, with a value of $p=0.001$. Conclusions: there is a correlation between breastfeeding technique skills and the incidence of abrasions in postpartum mothers. Suggestion: It is expected that health workers can provide health education on how to correct breastfeeding techniques so as to improve the skills of mothers in breastfeeding as one of the efforts to reduce the incidence of scalded nipples and the success of exclusive breastfeeding.

Keywords: breastfeeding technique skills, the incidence of blisters

\section{PENDAHULUAN}

Bayi baru lahir sangat rentan terhadap bergabagai macam infeksi yang mengancam kelangsungan hidup. Bayi yang tidak di berikan ASI pada awal kehidupannya akan beresiko terkena berbagai penyakit infeksi. Penyakit infeksi yang sering terjadi pada bayi diantaranya diare. Dampak yang harus diwaspadai pada bayi tidak mendapat ASI adalah kematian bayibaru lahir.

Penelitian yang dilakukan oleh Agrasada, et, al., mengidentifikasi bahwa 71,4\% bayi baru lahir yang tidak mendpatkan ASI menderita diare, sehingga bayi mengalami dehidrasi dan akhirnya meninggal, infeksi pada saluran penafasan merupakan penyakit kedua terbesr $57,1 \%$ yang timbul pada bayi karena tidak mendapatkan ASI. Saat menyusui, ibu sering kali menemui berbagai hambatan dan keluhan dari kesulitan saat menyusui, ASI tidak keluar dengan lancar, putting payudara yang luka, sampai sibuah hati yang rewel karena belum bisa menyusui dengan benar (Indiarti, 2007).

Menurut Mulyani (2013), agar proses menyusui berjalan dengan lancar, maka seorang ibu harus mempunyai keterampilan menyusui agar ASI dapat mengalir dari payudara ibu ke bayi secara efektif.

Berdasarkan data Dirjen Bina kesehatan Depkes tahun 2003 menyatakan bahwa pemberian ASI pada 30 menit pertama bayi baru lahir hanya 8,3\%-4,36\% pada satu jam pertama bayi baru lahir, 3,7\% bayi yang memperoleh ASI pada hari pertama (Maryunani, 2012).

Menurut WHO (World Health Organization), 2005, bayi yang diberi susu selain ASI (Air Susu Ibu), mempunyai 17 kali lebih mengalami diare, dan tiga sampai empat kali lebih besar kemungkinan terkena ISPA dibandingkan dengan bayi yang mendapat ASI (Depkes RI, 2005). 
Data Susenas (2007-2008) cakupan pemberian ASI eksklusif pada bayi 0-6 bulan di Indonesia menunjukkan penurunan dari 62,2 \% (2007) menjadi 56,2 \% (2008). Sedangkan cakupan pemberian ASI eksklusif pada bayi sampai 6 bulan turun dari 28,6 \% (2007) menjadi $24,3 \%$ (2008). Sementara jumlah bayi di bawah enam bulan yang diberi susu formula meningkat dari 16,7 \% pada 2002 menjadi 27,9\% pada 2003 (Riskesdas, 2010).

Menurut Profil Kesehatan Aceh Tahun 2011 bayi yang mendapat ASI eksklusif baru mencapai $11,9 \%$. Rendahnya cakupan ini banyak dipengaruhi oleh budaya memberikan makanan dan minuman terlalu dini kepada bayi baru lahir, akibat dari pengetahuan keluarga tentang ASI yang masih minim. Disamping itu gencarnya propaganda susu formula terutama diperkotaan dan perilaku ibu terhadap pemberian ASI (Dinkes Aceh, 2011).

Menurut Profil Kesehatan Aceh Besar tahun 2012, persentase bayi yang diberi ASI eksklusif baru mencapai 32,2 persen, yaitu dari jumlah bayi yang menyusu sebanyak 5263 orang bayi, hanya 1693 saja yang mendapat ASI eksklusif (Dinkes Aceh Besar, 2012).

Data Puskemas Peukan Bada menunjukkan pada tahun 2015, dari 426 ibu melahirkan terdapat $142 \mathrm{ibu}$ yang menyusui bayinya (30\%). Sedangkan pada tahun 2016 terhitung pada bulan Maret dari 32ibu yang melahirkan terdapat $12 \mathrm{ibu}$ yang menyusui bayinya $(37,5 \%)$ secara eksklusif dan $20(62,5 \%)$ ibu yang tidak menyusui bayinya secara eklusif. Alasan ibu tidak menyusui bayinya yaitu karena ASI tidak lancar, puting susu lecet serta alasan lainnya (Puskesmas Peukan Bada 2016 ).

Dari hasil wawancara dengan ibu post partum diperoleh dari 10 ibu post partum terdapat 7 orang ibu post partum mengeluh puting susunya lecet atau nyeri pada saat menyusui bayinya.

\section{METODE PENELITIAN}

Penelitian ini bersifat analitik dengan desain cross sectional. Pengumpulan data ini telah dilaksanakan pada tanggal 15 s.d 28 Desember 2016 di Wilayah Kerja Puskesmas Peukan Bada. Subjek dalam penelitian ini adalah ibu post partum 0-40 hari yang berada di Wilayah Kerja Puskesmas Peukan Bada pada bulan Desember tahun 2016. Jumlah ibupost partum 40 orang. Penelitian ini mengambil seluruh populasi (total population) pada bulan Desember 2016. Instrumen penelitian ini berupa lembaran observasi tentang kejadian puting susu lecet yang diisi peneliti dan lembaran daftar tilik tentang keterampilan ibu menyusui yang diisi peneliti. Cara penilaian yang digunakan adalah memberikan tanda checklist (v) 
pada kolom yang tersedia. Jika jawabannya Ya nilainya 2 dan jika jawabannya Tidak nilainya. Untuk menguji hipotesa dilakukananalisisstatistikdengan menggunakan uji chisquare test pada tingkat kemaknaannya $\mathrm{CI}=95 \%, \alpha=5 \%(0,05)$.

\section{HASIL DAN PEMBAHASAN}

Tabel 1. Distribusi Frekuensi Keterampilan Teknik Menyusui pada Ibu Nifas Di Wilayah Kerja Puskesmas Peukan Bada Aceh Besar Tahun 2016

\begin{tabular}{llcc}
\hline No & Keterampilan Tehnik Menyusui & f & Presentasi (\%) \\
\hline 1. & Baik & 20 & 41,7 \\
2. & Cukup & 14 & 29,2 \\
3. & Kurang & 14 & 29,2 \\
\hline & & $\mathbf{4 8}$ & $\mathbf{1 0 0}$ \\
\hline
\end{tabular}

Berdasarkan Tabel di atas menunjukkan bahwa dari 48 responden terdapat mayoritas responden dengan keterampilan baik yang berjumlah 20 orang $(41,7 \%)$.

Tabel 2. Distribusi Frekuensi Kejadian Puting Susu Lecet Pada Ibu Nifas Di Wilayah Kerja Puskesmas Peukan Bada Aceh Besar Tahun 2016

\begin{tabular}{llccc}
\hline No & & Puting Susu Lecet & f & Presentasi (\%) \\
\hline 1. & Tidak & & 26 & 54,2 \\
2. & Ya & & 22 & 45,5 \\
\hline & & Jumlah & $\mathbf{4 8}$ & $\mathbf{1 0 0}$ \\
\hline
\end{tabular}

Berdasarkan Tabel di atas menunjukkan bahwa dari 48 responden didapatkan sebagian besar yang tidak mengalami puting susu lecet berjumlah 26 orang $(54,2 \%)$.

Tabel 3. Hubungan Keterampilan Teknik Menyusui dengan Kejadian Puting Susu Lecet Pada Ibu Nifas Di Wilayah Kerja Puskesmas Peukan Bada Aceh Besar Tahun 2016

\begin{tabular}{lccccccc}
\hline \multirow{2}{*}{ Keterampilan Ibu } & \multicolumn{4}{c}{ Putting Susu Lecet } & \multicolumn{2}{c}{ Total } & \multirow{2}{*}{ P value } \\
\cline { 2 - 7 } & \multicolumn{2}{c}{ Tidak } & \multicolumn{2}{c}{ Ya } & \multicolumn{2}{c}{} \\
\cline { 2 - 8 } & $\mathbf{f}$ & $\mathbf{\%}$ & $\mathbf{f}$ & $\mathbf{\%}$ & $\mathbf{f}$ & $\mathbf{\%}$ & \\
\hline Baik & 16 & 80 & 4 & 20 & 20 & 100 & \\
Cukup & 8 & 57 & 6 & 43 & 14 & 100 & 0.001 \\
Kurang & 2 & 14 & 12 & 86 & 14 & 100 & \\
\hline \multicolumn{1}{c}{ Jumlah } & $\mathbf{2 6}$ & & $\mathbf{2 2}$ & & $\mathbf{4 8}$ & & \\
\hline
\end{tabular}


Berdasarkan tabel 5.3 diatas dapat dilihat bahwa kejadian puting susu lecet lebih banyak di jumpai pada responden dengan keterampilan kurang yaitu 86\% dibandingkan dengan responden yang keterampilan baik yaitu 20\%. Setelah dilakukan uji statistik chisquare di peroleh nilai p-value 0,001 $(\mathrm{P}<0,05)$, menunjukkan adanya hubungan antara keterampilan teknik menyusui dengan kejadian putting susu lecet.

\section{Pembahasan}

Berdasarkan Tabel 3 di atas menunjukkan kejadian puting susu lecet lebih banyak di jumpai pada responden dengan keterampilan kurang yaitu $86 \%$ dibandingkan dengan responden yang keterampilan baik yaitu $20 \%$.

Setelah dilakukan uji staststik maka diperoleh nilai $\mathrm{P}$-valu=0,001 yang menunjukkan adanya hubungan keterampilan teknik menyusui dengan kejadian puting susu lecet pada ibu nifas di wilayah kerja Puskesmas Peukan Bada Kabupaten Aceh Besar Tahun2016.

Penelitian Muraya, R (2016) tentang efektifitas demonstrasi teknik menyusui terhadap kejadian putting susu lecet dan keterampilan ibu menyusui pada ibu post partum, bahwa kelompok yang diberikan perlakuan yaitu berupa demonstrasi teknik menyusui didapatkan 13,6 \% yang mengalami putting susu lecet dibandingkan pada kelompok control (tidak diberi perlakuan) terdapat $86,4 \%$ yang mengalami putting susu lecet.

Menurut Mulyani (2013), agar proses menyusui berjalan dengan lancar, maka seorang ibu harus mempunyai keterampilan menyusui agar ASI dapat mengalir dari payudara ibu ke bayi secara efektif. Keterampilan menyusui yang baik meliputi posisi menyusui dan perlekatan bayi pada payudara yang tepat.

Menurut asumsi peneliti keterampilan dalam tehnik menyusui berpengaruh terhadap kemampuan ibu dalam memberikan ASI pada bayinya, diantaranya tentang bagaimana posisi menyusui, perlekatan mulut bayi pada payudara yang tepat, sehingga bayi dapat dengan mudah menghisap puting susu ibu, dan cara ibu memegang bayi pada saat menyusui, dengan demikian dapat mengurangi kejadian puting susu lecet. Posisi yang nyaman untuk menyusui sangat penting, ada banyak cara untuk memposisikan ibu dan bayi selama proses menyusui berlangsung.

Teknik menyusui yang salah dapat mengakibatkan terjadinya lecet puting susu atau masalah lain dalam menyusui, tetapi lecet puting susu dapat juga disebabkan oleh perawatan payudara yang salah misalnya membasuh payudara terutama puting susu dengan 
menggunakan sabun, thrush (candidates) dan dermatitis. Sebagian besar areola mamme harus sedapat mungkin masuk ke mulut bayi, sehingga puting susu berada dibawah langit-langit dan lidah bayi akan menekan ASI keluar dari tempat penampungan ASI yang terletak dibawah areola. Apabila bayi hanya menghisap pada puting saja, maka akan mengakibatkan lecet pada puting susu ibu

Kejadian puting susu lecet dapat dicegah melalui pendidikan kesehatan yang diberikan pada ibu dapat dilakukan dengan beberapa cara, yaitu melalui demonstrasi, prktek menggunakan boneka, vidio melihat bagaimana cara menyusui yang benar pada bayi baru lahir melalui pendamping atau bimbingan dari petugas kesehatan, penyuluhan, pemberian media leaflet, flipchart, dan lain-lain, dalm proses menyusui merupakan pendidikan kesehatan lanjutan bagi ibu menyusui. Kejadian puting susu lecet dapat dicegah dengan memberikan informasi pada ibu dan keluarga dalam memberikan ASI pada bayinya yang benar dan baik, melakukan demonstrasi tehnik menyusui yang benar. Peran petugas kesehatan dalam memberikan informasi melalui konseling pada saat mendampingi ibu menyusui bayinya.

Masalah kejadian puting susu lecet terletak pada hal yaitu pertama karena lingkungan, pengetahuan dalam tehnik menyusui. Dan yang paling penting ialah kebiasaan yang dilakukan oleh keluarga atau dari nenek moyang individu tersebut.

\section{DAFTAR PUSTAKA}

Departemen Kesehatan R.I. (2005). Rencana Strategi Departemen Kesehatan. Jakarta: Depkes RI

Indiarti, MT, 2007. A To Z The Golden Age, Yogyakarta : Amdi

Maryunani, A, 2012. Inisiasi Menyusui Dini, ASI Ekslusif Dan ManajmenLaktasi, Jakarta : CV. Trans Info Media

Mulyani, 2013. Asi Dan Pedoman ASI Ibu Menyusui, Yogyakarta : Nuha Medika

Muraya, R, 2016 . Efektifitas Demonstrasi Teknik Menyusui Terhadap Kejadian Putting Susu Lecet Dan Keterampilan Ibu Menyusui Pada Ibu Post Partum, Skripsi. Universitas Ubudiyah Indonesia.

Profil Dinas Kesehatan Aceh 2011

Profil Dinas Kesehatan Aceh Besar 2012

Riskesdas, 2010. Laporan Nasional Riset Kesehatan Dasar. Kementerian Kesehatan RI 